\title{
LOS NO-ANIMALES Y LA CATEGORÍA "ANIMAL". DEFINIENDO LA ZOO- SOCIOCOSMOLOGÍA ENTRE LOS TOBA (QOM) DEL LOS CHACO ARGENTINO
}

Celeste Medrano

\section{Presentación}

Para aproximarnos al mundo de manera analítica es preciso "disecarlo" a partir de categorías que agrupen elementos que posean rasgos comunes para observarlos luego de manera conjunta. Así, vamos dotando a estas etiquetas clasificatorias de atributos, significados y las organizamos en esquemas clasificatorios que confieren orden a una escena que, al principio, parece sujeta por el caos. Cuando nos enfrentamos a la zoología de otras sociedades, lo hacemos con el bagaje de nuestras propias categorías clasificatorias del entorno biológico que, en numerosas ocasiones, se enfrentan y se ponen en perspectiva con la manera diferente que esos "otros" tienen de concebirse en relación a los animales. A este ejercicio se han dedicado numerosos etnógrafos quienes lograron cuestionar la propuesta occidental que ubica a la naturaleza en la esfera de "lo dado" y a la cultura en el terreno de "lo construido".

Uno de los principales exponentes de estos análisis es Philippe Descola (1996 [1986]) quién dio cuenta de cómo los achuar de la Amazonía ecuatoriana se relacionaban práctica y simbólicamente con el medio. En su etnografía, empleó categorías como las de "hombres", "seres de la naturaleza" (que reunía a plantas, animales y "jefes de los animales") y "espíritus". Esta última etiqueta clasificatoria incluía a las "madres de la caza" -seres que ejercían una influencia sobre el mundo animal-, "gentes del agua" y otros "espíritus sobrenaturales" que no ejercían influencia sobre el mundo animal. Descola concluyó que "la relación de la naturaleza con la cultura se deja ver menos como una ruptura que como un continuum", aspecto que determina que entre los achuar no se encuentre una "antinomia entre dos mundos cerrados e irreductibles opuestos: el mundo cultural de la sociedad humana y el mundo natural de la sociedad animal" (:434). 
Bruno Latour (2007 [1991]) retomó los datos etnográficos de Descola para profundizar la discusión sobre la distancia que existe entre naturaleza y cultura. De acuerdo a esta propuesta, la modernidad habría logrado su expansión separando con cuidado la naturaleza de la sociedad. Latour sostiene que la palabra "moderno" designa dos conjuntos de prácticas: "el primer conjunto de prácticas crea, por 'traducción', mezclas entre géneros de seres totalmente nuevos, híbridos de naturaleza y cultura. El segundo, por 'purificación', crea dos zonas ontológicas por completo distintas, la de los humanos, por un lado, la de los no-humanos, por el otro" (:28). Con base en el análisis de la relación entre estos últimos colectivos -el de los humanos y el de los no-humanos (identificado como todo aquello que no es humano)-, comenzaron a discurrir aquellos estudios que, a comienzos del siglo XXI, redoblaron esfuerzos por comprender qué hay de natural en la cultura y qué hay de cultural en la naturaleza.

En 2005, Descola publica Par-delà nature et cultura, en donde sienta las bases de cuatro ontologías establecidas en función de las características que humanos y no-humanos tendrían respecto de su interioridad y su fisicalidad. Este autor afirma que numerosos pueblos indígenas amerindios y no-amerindios tendrían una concepción del mundo animista de acuerdo a la cual "los humanos le atribuyen a los no-humanos una interioridad idéntica a la suya" (Descola 2012:199). Al existir una continuidad en la interioridad de los seres, "la forma es el criterio crucial de la diferenciación en las ontologías animistas" (:201), o también "el cuerpo es el diferenciador ontológico" (:204). De acuerdo a estos enunciados, la taxonomía de los seres se anclaría en aquellos atributos externos que definen un determinado régimen corporal. Anne Christine Taylor, quién trabajó junto a Descola entre los achuar, asevera que "lo que distingue a las especies es, en definitiva, el hábito" (1998:323-324).

Las etnografías amerindias que se produjeron posteriores a la propuesta elaborada por Descola (1996 [1986]) ${ }^{1}$ o retomando las ideas de Latour (2004, 2007) trataron a los no-humanos como una categoría algo homogénea. Sin embargo, el mismo Latour advierte que se usa la expresión de no-humanos como sinonimia de proposiciones o relaciones y que la misma "no tiene ninguna otra significación además de la negativa" (2004:378). Esta categoría debe ser matizada a la hora de intentar comprender la forma en que distintas sociedades indígenas, con ontologías diametralmente opuestas a la que lleva implícita la zoología académica occidental, piensan y se relacionan con las especies animales. Enunciado que sostenemos luego de nuestro trabajo etnográfico con los toba.

Los toba o qom son un grupo indígena que perteneces a la familia lingüística Guaycurú. Representan una sociedad indígena cazadora-recolectora 
que desarrollaba su vida nomadizando en el Gran Chaco. ${ }^{2}$ Luego de los violentos procesos de conquista y colonización, muchos toba modificaron su estilo de vida hacia dos grandes patrones de asentamiento. Unos tendieron hacia la sedentarización en los territorios que el Estado les concedió, mientras que otros migraron en los años sucesivos a la periferia de las grandes ciudades de Argentina. El trabajo agrícola en la propia tierra o como cosecheros en las de los criollos y, en menor medida, la caza, pesca y recolección, continúan hasta el presente con diversos grados de desarrollo según las zonas. Los estudios sobre la organización social de los toba sugieren que, antes del siglo XIX, estos indígenas se movilizaban como familias extensas matrilocales que, aglutinadas en "bandas", se constituían como unidades locales, las que se congregaban en "tribus". Se trataba de unidades políticas agrupadas en torno a una misma variante dialectal que se desarrollaban estableciendo alianzas mediante las relaciones de parentesco a través del intercambio matrimonial (Braunstein 1983). La cosmovisión y religiosidad toba previa a la llegada del cristianismo presentaban similitudes con las de otros pueblos cazadores recolectores, basadas en "complejos animalísticos", es decir, en un esquema jerárquico muy desarrollado de dueños de animales, estrechamente vinculados con los principios culturales de clasificación del espacio, con las regulaciones de caza y con la iniciación y práctica chamánica (Cordeu \& Siffredi 1971).

En la década de 1940 comenzó a difundirse el pentecostalismo, a partir de una serie de misioneros que arribaron a la región. Ese proceso provocó el abandono, en unos casos, y la transformación, en otros, de las prácticas rituales anteriores del grupo, así como la incorporación de nuevas formas, dando origen al movimiento de iglesias indígenas conocido como "evangelio" (cf. Wright 2002; Ceriani Cérnadas 2013). En 1961 el movimiento obtuvo el estatuto legal para realizar sus cultos, convirtiéndose en la primera iglesia indígena autónoma de la Argentina: la Iglesia Evangélica Unida (Wright 2002).

Este artículo se basa en investigaciones etnográficas efectuadas a lo largo de 2008 a 2012, por un período total de 11 meses, en las comunidades toba de Riacho de Oro, San Carlos y Kilómetro 503 del departamento Patiño (Formosa) y El Desaguadero, El Naranjito, el barrio toba Nlaxayec ${ }^{3}$ (La Paz) y 12 de octubre (ubicados dentro del ejido urbano de la ciudad de El Colorado) del departamento Pirané, así como en el barrio periurbano Namqom ubicado a 11 kilómetros de la ciudad de Formosa. Nos dedicaremos particularmente a comparar aquellos atributos que definen a los humanos y a los no-humanos con el fin de complejizar a este último colectivo dentro del cual se encuentran los animales. Si, como propone Descola, "la forma corporal es indisociable del comportamiento inducido por ella" (2012:207), nos abocaremos a identificar los distintos regímenes corporales y la etología vinculada a los 
mismos. Asimismo, privilegiaremos un análisis emic de las categorías con el fin de alcanzar una clasificación que responda a cómo los qom piensan su zoo-sociocosmología. Este último término fue elaborado por nosotros (Medrano 2012) para dar cuenta de una zoología que no puede ser comprendida al margen del marco sociocosmológico en el que se piensan los indígenas. En definitiva esta constituye una forma de ver, relacionarse, comprender, y conceptualizar a los animales, que no puede despegarse del trasfondo de dimensiones institucionales (parentesco, organización social) e ideológicas (sistemas de clasificación, ontologías) mediante las cuales los humanos organizan sus prácticas y su universo simbólico (Medrano 2014b:257).

\section{Taxonomías qom}

A continuación analizaremos la macrotaxonomía qom, o sea, las categorías superiores que ordenan a los seres. Las primeras referencias respecto de este tema describen cómo es organizado el universo toba. Se determinó que el mismo se encuentra estructurado en tres niveles -cielo, tierra y profundidades acuáticas- los cuáles, a su vez, se hallan divididos en cinco estratos. Los indígenas desarrollarían su vida sobre 'alhua (tierra), la superficie de la tierra, y establecerían múltiples vínculos con los pigueml'ec (habitantes del cielo), los 'alhual'ec (habitantes de la tierra) y los ne'etaxaal'ec (habitantes de las profundidades acuáticas) (Miller 1979:35-38). ${ }^{4}$

En sintonía con estos planteos, Pablo Wright (2008) se aventuró en un bosquejo de la macrotaxonomía toba que llevó adelante mediante un "experimento cognitivo" que intentaba delinear los límites de la taxonomía animal qom. La experiencia consistía en presentar a sus interlocutores dibujos anómalos que el antropólogo Luis Vuoto (1981a, 1981b) (interesado por la etnozoología qom) diseñó. La propuesta resultó sugestiva y Wright concluyó que "como consecuencia de este estudio, pudo figurarse una idea aproximada de la normalidad y anormalidad en la zoología qom" (:142). Expresó que el nicho habitual de los animales es la tierra firme y caracterizó a los no-humanos -incluyendo dentro de éstos a los dueños de las especies y a otros seres con forma humana- que, dotados de gran poder, viven en el resto de los estratos del universo qom. Finalmente, afirmó que el "ser parece estar definido no sólo por la pertenencia a las categorías humano/no-humano, sino también por lugares y/o nichos cosmológicos" (:150) donde los humanos son definidos gracias a sus relaciones de poder con los no-humanos. Wright expresa que la distinción general humano/no-humano asocia "a los primeros con 'día', 'luz' y 'este', y a los segundos con 'noche', 'oscuridad' 
y 'oeste'" (2008:148). En su propuesta la categoría no-humanos parece no incluir a los animales.

Estos análisis, centrados casi exclusivamente en una comparación entre el poder diferencial de los humanos y los no-humanos, nos permite una escasa aproximación a la noción toba de "animal" y su relación con el resto de los existentes. ${ }^{5}$ En palabras de Florencia Tola, estas contribuciones no "visualizaron a los otros seres como verdaderas personas dotadas de capacidad de acción, conciencia reflexiva, intencionalidad y vida social" (2012:76). Es necesario revisar entonces las características que definen a los diversos seres en la sociocosmología qom. Para ello, comenzaremos precisando los aspectos que delinean a la persona toba para luego compararlos con aquellos que poseen los animales.

\section{Shiỹaxaua}

Para los qom, la palabra shiỹaxaua, que en términos generales podría traducirse como "persona", define tanto a los seres humanos como a otros de naturaleza semejante a la de los humanos que habitualmente se incluyen en la categoría de "no-humanos". Elegimos por ahora llamarlos "otras personas". Para graficar lo que proponemos y como guía para el desarrollo del texto, diagramamos un esquema provisorio (Figura 1) que, en base a nuestros datos de campo, discrimina al mundo de los existentes qom asignándoles las características gracias a las cuáles los indígenas los identifican.

En su análisis de la vida social de las "otras personas", Tola explica que los qom las denominan ỹoqta siỹaxaua (verdaderas personas). Esta categoría comprende a la "gente del monte" (aviaq le'c), la "gente del agua" ('etaxat $\left.l e^{\prime} c\right)$, la "gente del campo" (no'onaxa l'ec), la "gente de la noche" (pe le'c) y la "gente del cielo" (piguem l'ec) que, dispuestas en los tres niveles celestes, incluirían a los dueños de los animales y las plantas, el dueño de la luna y a quiyoc lta'a (lit. "padre del jaguar") (2012:80). Un somero análisis lingüístico nos revela la alineación de estos seres dentro de las personas. La expresión qom le'c se emplea para describir a un "hombre toba", la expresión 'etaxat $l e^{\prime} c$ para un "hombre del agua". Cúneo señala que "Las formas llek [le'c] y lashe señalan origen o pertenencia de un ser humano como 'perteneciente a' o 'habitante de'. En la lengua, poseen una función destacada en la conformación de etnónimos" (2013:271). De acuerdo al estudio de la autora, también se usan, desde el punto de vista semántico, para codificar nombres de aves de acuerdo a su lugar de pertenencia o variedades de un tipo de animal (:271-274). Veamos qué características de estas "otras personas", sintetizadas en la Figura 1, los tornan similares a los humanos y cuáles los diferencian de estos. 


\section{Figura 1: Humanos, no-humanos y sus atributos}

\begin{tabular}{|c|c|c|c|c|c|c|}
\hline \multicolumn{2}{|c|}{ Categorías } & \multirow{2}{*}{\begin{tabular}{|l|}
\multicolumn{1}{|c|}{ Forma } \\
\\
$\begin{array}{l}\text { Forma } \\
\text { humana, } \\
\text { poder } \\
\text { metamórfico } \\
\text { menor }\end{array}$ \\
\end{tabular}} & \multirow{2}{*}{$\begin{array}{c}\begin{array}{c}\text { Régimen } \\
\text { alimentario }\end{array} \\
\text { Animales }\end{array}$} & \multirow{2}{*}{$\begin{array}{c}\begin{array}{c}\text { Régimen } \\
\text { sexual/ } \\
\text { reproductivo } \\
\text { preferencial }\end{array} \\
\text { Con personas }\end{array}$} & \multirow{2}{*}{$\begin{array}{l}\text { Hábitat } \\
\text { Casas }\end{array}$} & \multirow{3}{*}{$\begin{array}{l}\text { Comportamiento } \\
\\
\text { Vida social, } \\
\text { desarrollo de } \\
\text { liderazgo y } \\
\text { parentesco, } \\
\text { capacidad } \\
\text { cognitiva y } \\
\text { facultad para } \\
\text { experimentar } \\
\text { emociones, } \\
\text { comunicación } \\
\text { lingüística }\end{array}$} \\
\hline Humanos & $\begin{array}{l}\text { Personas } \\
\text { shiỹaxaua }\end{array}$ & & & & & \\
\hline \multirow[t]{3}{*}{$\begin{array}{c}\text { No- } \\
\text { humanos }\end{array}$} & $\begin{array}{c}\text { "Otras } \\
\text { personas" } \\
\text { shiyaxaua }\end{array}$ & $\begin{array}{l}\text { Forma } \\
\text { humana, } \\
\text { poder } \\
\text { metamórfico } \\
\text { mayor }\end{array}$ & $\begin{array}{l}\text { Animales, } \\
\text { pescados, } \\
\text { pueden } \\
\text { predar } \\
\text { personas }\end{array}$ & $\begin{array}{l}\text { Con "otras } \\
\text { personas" }\end{array}$ & $\begin{array}{l}\text { Monte, } \\
\text { agua, } \\
\text { campo, } \\
\text { cielo }\end{array}$ & \\
\hline & $\begin{array}{l}\text { Animales } \\
\text { shiguiỹac }\end{array}$ & $\begin{array}{l}\text { Forma } \\
\text { animal, } \\
\text { poder } \\
\text { metamórfico } \\
\text { menor }\end{array}$ & $\begin{array}{l}\text { Otros } \\
\text { animales y } \\
\text { vegetales, } \\
\text { pueden } \\
\text { predar } \\
\text { personas }\end{array}$ & Con animales & $\begin{array}{l}\text { Monte, } \\
\text { agua, } \\
\text { campo }\end{array}$ & \multirow{2}{*}{$\begin{array}{l}\text { Vida social, } \\
\text { desarrollo de } \\
\text { liderazgo y } \\
\text { parentesco, } \\
\text { capacidad } \\
\text { cognitiva y } \\
\text { facultad para } \\
\text { experimentar } \\
\text { emociones, } \\
\text { comunicación } \\
\text { extralingüística }\end{array}$} \\
\hline & $\begin{array}{c}\text { "Otros } \\
\text { animales" } \\
\text { shiguiyac }\end{array}$ & $\begin{array}{l}\text { Forma } \\
\text { animal, } \\
\text { poder } \\
\text { metamórfico } \\
\text { mayor }\end{array}$ & $\begin{array}{l}\text { Otros } \\
\text { animales y } \\
\text { vegetales, } \\
\text { pueden } \\
\text { predar } \\
\text { personas }\end{array}$ & $\begin{array}{l}\text { Con "otros } \\
\text { animales" }\end{array}$ & $\begin{array}{l}\text { Monte, } \\
\text { agua, } \\
\text { campo, } \\
\text { cielo }\end{array}$ & \\
\hline
\end{tabular}

Por ejemplo, entre los 'etaxat le'c se ubica veraic. Éste es descripto como "una personita del agua, muy morocho, negro, con pelito muy bajo y rulo, y tiene mucha fuerza" (Valentín). Según afirman los qom, veraic tiene dominio sobre el mundo acuático e incide sobre la cantidad de peces que los hombres pueden obtener. Bajo el agua existe un gran número de estas personitas que, organizadas en familias, participan de relaciones matrimoniales, se reproducen al igual que los humanos y tienen hijos. Prueba de esto último es el relato de un pescador que en cierta oportunidad se encontraba sumergido en el río pescando con su red y, como esta se había puesto pesada, se trasladó afuera del agua para observar su presa. En la orilla comprobó que dentro de la misma había un veraic llalec (lit. "hijo de veraic") que lloraba al igual que lo hacen los niños humanos. El hombre decidió entonces liberarlo. El pequeño veraic se alejó hacia las profundidades acuáticas y el pescador concluyó: "para qué vamos a llevar si no son del seco [tierra seca]?". Otras evidencias dan cuenta de la existencia de jefes responsables de conducir la vida en las profundidades y de otros seres que se desempeñarían como guardianes de las moradas de los veraic. También 
sabemos que estas personitas se alimentan de pescado y otros animales que pueden conseguir dentro del agua.

Huashe es una aviaq lashe o una "mujer del monte". Posee un cuerpo pequeño por lo cual los cazadores suelen descubrir su presencia en el monte observando sus pequeñas pisadas. Algunos qom expresaron que esta mujer suele solicitar relaciones sexuales cuando se encuentra con hombres y, si estos no acceden a su pedido, pueden perder la suerte en la marisca ${ }^{6}$ o sufrir trastornos permanentes de erección. Ella es considerada peligrosa por esto y porque, cuando encuentra niños en el monte, puede "secuestrarlos y llevarlos para su familia" (Valentín). Al igual que todas las mujeres, también envejece, tal como enseña Vilo: "huashe se nota cuando es vieja o joven porque tiene canas".

Algunos mariscadores nos trasmitieron que, en el monte, se pueden mantener diálogos con estas "otras personas" con el fin de, por ejemplo, ubicar panales de abeja. Sin embargo, siempre tiene que mediar una relación de respecto para no despertar la ira o el mal humor de estos seres. Como enuncia Clemente:

Un señor una tarde le vio a ese hombrecito y le dice [que dijo ese hombrecito]: "acá donde estoy apuntando está una miel". Entonces el hombre se fue y esa miel estaba medio arriba del palo y dijo: "bueno voy a subir". Entonces [...] se cayó para atrás, se hizo mal y dijo: "con razón que me mandó ese, para que me caiga". Entonces a la noche se fue [a hablar con el hombrecito del monte] y le dijo: "¿Por qué me dijiste así hoy?". [El hombrecito contestó] "¿Acaso que yo te obligué a subir? Vos nomás subiste, ahora si yo te obligo sí. Pero ahora nunca jamás vas a encontrar miel". Y nunca más encontró miel porque le habló mal al hombrecito del monte y [éste] se enojó.

Otro de los aviaq le'c (hombre del monte) es qosorot, quién también posee forma humana y puede comunicarse con los cazadores para otorgarles la habilitad de encontrar presas.

Como puede apreciarse en esta somera descripción de las "otras personas", ellas, al igual que los humanos, desarrollan una socialidad caracterizada por la vida en familia y el despliegue de liderazgos, experimentan emociones y se comunican con los humanos empleando el lenguaje verbal. Una de las diferencias que encontramos entre los regímenes corporales de las personas y de las "otras personas" radica en que estas últimas tienen un gran poder transformacional, pudiendo adoptar forma animal o humana de acuerdo al contexto de interacción y a la situación comunicacional (Medrano 2013, 2014a). 
Otra de las diferencias se vincula con la potencialidad que tienen las "otras personas" de predar gente, hecho que las torna peligrosas y las ubica en una relación asimétrica respecto de los qom. Para comprender esta relación, seguimos lo propuesto por Tola (2010), quién indica que los humanos deben someterse a los dueños de las especies con el fin de obtener presas para sobrevivir. A su vez, los dueños despliegan actitudes ambivalentes que se vinculan con la compasión o con la predación, relaciones que conducen a la autora a sostener la existencia de una complejidad asimétrica que determina la capacidad de acción de los seres en el universo qom. Fausto, en su análisis sobre la noción de "dueños" en la Amazonía, explica que la razón del relativo escaso tratamiento del tema se vincula "a uma visão bastante comum sobre as terras baixas da América do Sul como uma província da igualdade e da simetria, em contraste com a hierarquia e a assimetria reinantes no Velho Mundo e no altiplano andino" (2008:329).

Igualdad y asimetría que no pueden ser sostenidas por lo menos en este rincón de las tierras bajas llamado Gran Chaco donde viven los toba. "Antes había una víbora grande y tiene pies y come gente", relató Clemente para inaugurar un relato que se vinculaba a como 'araxanaq late'e (lit. "madre de las serpientes") cuida de un curso de agua próximo a la comunidad y puede predar humanos si la situación la desconforma. Además, existen en los cuerpos de agua seres que no poseen un nombre definido pero sí una forma humana y rasgos homicidas, tal como enunció Carlos cuando relató el motivo por el que su canoa se dio vuelta en un sector de la laguna donde pescaba habitualmente: "soné esa noche que vinieron un shiỹaxaua, 'etaxat le'c [persona, hombre del agua]. Que me hablaban, ese lugar está mezquinando que nadie puede cruzar o [estar] jodiendo [molestando]. Ese hombre en sueños me contó: 'yo soy un hombre matador de cualquier persona, así que dejen'".

Dentro de estas "otras personas" se ubicarían los dueños de las especies animales y vegetales. Al igual que para los candoshi, para quiénes "las 'madres' [de las especies] pueden tener la forma de un prototipo de la especie en cuestión o adoptar una apariencia antropomórfica" (Surrallés 2009:170), para los qom estos seres poseen un alto potencial transformacional, presentándose alternativamente como shiỹaxaua o como shiguiỹac (animal). Cuando Segundo brindaba detalles sobre el dueño de la miel, comentaba:

En el monte diferente miel hay [...]. Y hay un señor que está cuidando también eso. Ese tipo [persona] todo lleno el cuerpo del vello, muy velludo. Ese es el cuidador [...]. Vos no sabés el nombre de tal miel y [él] viene a conversar con vos, este nombre tal, recién vos sabés, porque te enseña. 
En este caso, el dueño de la miel no sólo vela por el recurso, sino también tiene la capacidad de nominar a las especies que custodia. Este antiguo cazador explicaba que "es como cuando un qom tiene un perro y tiene que colocarle un nombre y hacerse responsable del mismo". Esta última información sugiere que los dueños de las especies desarrollan, a su modo, relaciones de domesticación con las especies que resguardan, vinculándolas, mediante ese proceso de socialización, a su vida familiar en el interior del monte.

Respecto a la comunicación entre los humanos y los no-humanos encontramos, por ejemplo, que entre los yagua de la Amazonía peruana, los chamanes establecen diálogos con "les esprits-maîtres"7 por medio de canciones, más exactamente de registros acústicos (Chaumeil 2010). La información recogida por Descola (1996) demuestra como los ashuar intercambian mensajes con los dueños de las especies de caza utilizando cantos de seducción, cuyo fin es propiciar la práctica cinegética encontrando la pista de las presas, logrando que éstas caigan de las ramas altas de los árboles luego de la agonía en la que las deja el curare, etc. Los qom, en cambio, emplean el qom l'aqtaqa (lengua toba) para comunicarse con los protectores de las especies animales o los guardianes de ámbitos como el río, el monte, la laguna.

Así, a través de ruegos, ${ }^{8}$ los indígenas solicitan encontrar animales para cazar, no sufrir accidentes durante la jornada, pero también declaran buenas intenciones y la voluntad de no derrochar las presas que se les otorga y realizar un tratamiento respetuoso de los restos no comestibles, como huesos, piel, plumas y escamas. Mauricio, un antiguo cazador toba, enunció la siguiente rogativa: 'Am no'ouet, aỹem 'achoxorem, aỹem 'anem ca na'achec ỹaqto shegueuo, nache deque'e ca ỹalaqpi. (Usted no'ouet, téngame compasión y hágame un favor para que me pueda ir a casa y puedan comer mis hijos). Cómo se lee, el mariscador habla en lengua qom con no'ouet, el dueño del monte, solicitando compasión. Esto último ilustra lo que enunciábamos más arriba respecto a la asimetría entre los humanos y los dueños de las especies: los toba a éstos les piden compasión, se ubican en una posición de inferioridad y desde allí suplican ayuda.

Cuando consultamos acerca de quién cuidaba a los guazunchos (Mazama spp.), un mariscador nos respondió que quien vela por estos animales es aviaq le'c, y agregó: "Hay otra especies de guazuncho que se cree que se transforma en aviaq le'ec. Porque son más semejantes [grandes] y muchas veces los cazadores lo tiran con el arma y no revienta la bala. Ese cuida" (Valentín). Otro cazador narró que quien resguarda a los guazunchos es ñi'imshi late'e (lit. "la madre de los guazunchos"). 
Esta información da cuenta, por un lado, del alto poder transformacional que tienen los dueños y, por otro, de la existencia de un sistema de dominio o cuidado que no es ni unívoco ni estable. Al guazuncho lo pueden proteger tanto las "otras personas" que viven en el monte, cualquiera sea su nombre, o la "madre de los guazunchos" que, al mismo tiempo, tiene el poder de metamorfosearse en persona o animal. Lo mismo ocurrió cuando indagamos sobre el dueño del carpincho (Hydrochaeris hydrochaeris). Nos respondieron que se podía tratar de un 'etaxat le'c (hombre del agua) -inclusive nos relataron una anécdota relativa al castigo que este ser le había proporcionado a los cazadores porque no habían respetado la regla de no maltratar las vísceras del animal muerto- pero también a los hualliquiaxai (carpincho) los cuida hualliquiaxai lta'a (lit. "el padre de los carpinchos"). Para resumir, estas "otras personas" que cuidan de los ambientes y las especies pueden adoptar una forma externa humana o animal. Esta evidencia da cuenta de una franja en donde las categorías shiỹaxaua y shiguiỹac se solapan debido a su participación en una cosmología profundamente atravesada por las transformaciones (cf. Medrano 2013).

Si las "otras personas" han sido definidas en diversas etnografías como no-humanos que -respecto a los humanos- poseerían una forma externa similar y un régimen corporal definido por rasgos excesivos, la evidencia de animales con idéntica forma externa y otro régimen corporal ìnos permitiría hablar de los no-animales? Nos dedicaremos a analizar esto.

\section{No-animales ${ }^{9}$}

Los qom les confieren determinados atributos a los animales (cf. Medrano 2012). No obstante, durante el devenir de nuestra investigación, percibimos la existencia de "otros animales". Para los toba, si bien estos "otros animales", son llamados shiguiỹac, muestran particularidades que los diferencian de los animales típicos. En principio, estas variaciones tienen que ver con los tamaños corporales (son más grandes o más chicos), las desviaciones respecto al cromatismo de partes corporales o del cuerpo entero y la posesión de estructuras dérmicas (cuernos, pelos) fuertemente desarrolladas. En segundo lugar, este viraje en la forma externa les posibilita habitar ambientes alternativos en relación a los que normalmente ocupan los animales, o desempeñar otras funciones sociales. Para arrojar luz sobre esto, hemos agrupado a los "otros animales" en divisiones que nos permitirán abordar una descripción de los mismos. ${ }^{10}$ 


\section{Los shiguiỹac lta'a y late'e}

Ya comentamos que los dueños de las especies animales y vegetales, identificados con las etiquetas nominales lta'a (padre) y late'e (madre), son principalmente shiỹaxaua, "otras personas". Además, en el léxico etnozoológico existen zoónimos animales y vegetales que se forman utilizando los términos de parentesco lta'a y late'e. No nos referiremos a estos shiguiỹac que tiene un régimen corporal típicamente animal, sino a los "otros animales" cuyos nombres se forman empleando el mismo léxico, tienen forma externa animal y cumplen funciones de protección del grupo de especies del que forman parte. $\mathrm{Al}$ respecto, Cúneo enuncia que

[...] no podemos afirmar que la lengua exhibe una categorización unívoca del mundo circundante, dado que los sistemas lingüísticos de clasificación nominal se solapan e interactúan. Diferentes sistemas de clasificación implican diferentes taxonomías, por lo que nuestro estudio confirma que no hay una relación uno a uno entre clasificación nominal (lingüísticamente codificada) y categorización ontológica o conceptual (cultural) (2013:345).

Por ejemplo, Hualliquixai lta'a (lit. "padre de los carpinchos"), tal como expresa Valentín, "es el macho, el más grande de todos. Y ese macho como [que] es el capitán de todos los hualliquiaxai se llama shiyac, es el que cuida". En este ejemplo, el tamaño es el que ayuda a un observador externo a identificar a este animal que, si bien tiene la forma externa de un carpincho, posee condiciones que lo tornan distinto. La tarea de estas "madres" y "padres" consiste en defender a los animales de su misma especie. Roberta, una qomlashe (mujer qom) que vive en Namqom, subrayó que muchos cazadores se cuidan de abusos cuando van a sacar la grasa del da'ailo'oc (yacaré: Caiman spp.) porque da'ailo'oc lta'a puede manifestar su enojo torciendo los dedos de estos hombres.

Estos "otros animales" tienen la facultad de aparecer y desaparecer de la vista de los humanos y trasmitir mensajes mediante un comportamiento distinto al del animal del que toman la imagen de referencia. Por ejemplo:

Un hombre que mariscó el colleguesaq lta'a (lit. "el padre de las iguanas"), dice que [es] más grande que la iguana (Tupinambis spp.), pero bien colorado. [...] El hombre que encontró eso en el medio del monte dice que hay una cueva grande y quería ver y cuando vio ya no está más. Entonces él lo buscaba, lo buscaba y no lo podía encontrar y tampoco dispara [se va]. Por eso dice que ese es el rey de la iguana, más grande que la iguana. Y cuando el hombre encontró eso, al momento se enfermó. Dice que anuncia algo y hasta que murió. Y a lo 
mejor el hombre estaba enfermo y ese anuncia que ese hombre va a enfermar y no van a curar más (Félix).

Como ya comentamos, ñi'imshi late'e es inmune a las balas, pero también utiliza la facultad de desaparecer y aparecer para perder en el monte a quienes pretenden cazarla. Evaristo comentó que, empecinado en dispararle, comenzó a perseguir a este "otro animal" y a internarse en ambientes que él no conocía. Así, llegó tan lejos y se sintió tan extraviado que tuvo que pernoctar en el monte y le llevó un tiempo considerable retornar a su casa. El hombre que me trasmitió esta información agregó que quién distrajo al cazador "no era guazuncho", a pesar de tener la misma forma, y explicó que "todos los animales tienen un jefe. El chancho jabalí (Tayassuidae) tiene un jefe, el 'tambor' se llama, todos los bichos tienen un cacique". Esta figura animal cumple un rol equiparable a la de los jefes de las bandas toba -o "caciques" en la literatura chaqueña más antigua- quiénes debían, entre otras funciones, guiar a la banda en sus derroteros anuales, anticipando y sorteando situaciones peligrosas gracias a sus facultades especiales, cómo la sabiduría, el coraje o los poderes chamánicos (cf. Métraux 1996). Asimismo, el "jefe de los chanchos jabalí" prevé las intenciones del cazador y decide cederle a sus protegidos, la "jefa de los guazunchos" tiene el poder de aparecer, desaparecer y ser resistente a los proyectiles humanos.

Al mismo tiempo, Martín, antes de enumerar detalles sobre la caza del ñandú (Rhea americana), señaló que "los mañic [ñandú] tienen un guía, ese es difícil matarlo, ese no se come, vigila todo el tiempo, es más grande". Tal como relata Ernesto, un cazador que vive actualmente en Riacho de Oro: "mañic lta'a es más grande y no muere, cuando le disparan, no sale la bala y si le tirás, abre las alas. Por eso, cuando vos te vas [a cazar], no tenés que decir nada, porque ese te va a escuchar y entonces todo el día vas a estar buscando [ñandú] y no vas a encontrar nada". En esta última evidencia, el tamaño vuelve a ser un diacrítico para la identificación de este "otro animal" al que hay que respetar en tanto líder de un grupo de animales importantes para la subsistencia de los qom.

Para los achuar, "cada especie es dotada de un jefe que primum inter pares vigila los destinos del grupo. Nombrado como amana, ese animal tiene un tamaño un poco superior al de sus congéneres y se disimula tan bien en la selva que lograr verlo es excepcional" (Descola 1996:352). Los amana, quienes constituyen los interlocutores privilegiados por los cazadores, son, junto a las "madres de la caza", invisibles a los hombres que se comunican con ellos por medios de los anent (cantos de encantamiento). Si la característica de identificación vinculada al tamaño de estos "otros animales" coin- 
cide con la información que encontramos, ella difiere en que los shiguiỹac lta'a y late'e entienden la lengua toba y no son interpelados por medio de canciones, sino por medio de rogativas como describimos arriba. Inclusive, un qom detalló cómo mañic lta'a, ofendido por un abuso en la caza de sus "protegidos" -materializado en la matanza de un número mayor de presas de las que se pueden consumir-, se transformó en persona y se apareció a la noche a "conversar con el mariscador para que deje de cazar" (Mauricio).

Los shiguiỹac lta'a y late'e esperan que los cazadores qom marisquen el número de presas justo y necesario que alcance para alimentar al grupo familiar, no maltraten a los restos de los cadáveres, no maten a las crías ni a las hembras embarazadas y enuncien rogativas solicitando permiso para introducirse en los espacios habitados por las especies animales. Si alguna de estas reglas son violadas, los "jefes de los animales" manifiestan su enojo produciendo enfermedades y hasta la muerte del cazador o de los miembros de su familia, al igual que lo hacen las "otras personas" vinculadas al cuidado de un grupo de animales o un ambiente.

\section{Los shiguiỹac n'natac}

Los shiguiỹac n'natac ${ }^{11}$-animales auxiliares chamánicos- se encuentran fuertemente vinculados con los pi'oxonaq (chamanes). De acuerdo a nuestra información, cualquier animal tiene la potencialidad de ser n'natac (auxiliar chamánico). Tal como describe Valentín de Riacho de Oro: “todos los demás animales los podemos decir en n'natac, [sea] cual sea el animal, quiyoc (tigre), huaxaỹaxa (zorro), palachiyaxa (araña), choit (lechuzón), huole (águila), qañaxaye (carancho), podría ser alguno que no está [en esta lista] pero son variedades, son muchos". Estos poseen una forma externa claramente animal, aunque su materialidad pueda fluctuar, pudiendo relacionarse con los chamanes como lqui'i ${ }^{12}$ o como un cuerpo concreto. Así lo muestra el siguiente ejemplo:

Por ejemplo 'exala, la culebra, hay algunas culebras que son verdes, y algunas culebras que son amarillas y negras, que anda por los pastizales, esa es una n'natac, de un pi'oxonaq. Por ejemplo, así estando en una casa empieza a silbar [el chamán] y en un ratito aparece 'exala. Aparece su n'natac. De día lo mismo, y una vez que aparece, la agarra, es una víbora, la agarra y la acaricia y le pone en el cuello, eso viste que la relación es víbora, no es espíritu, es un animal, pero es el n'natac de ese pi'oxonaq.

La relación que estos "otros animales" establecen con los pi'oxonaq les permite a estos últimos obtener noticias climáticas y de diversas esferas 
del medio biológico, curar o provocar enfermedades y trasladarse. Así, un chamán que tenga como n'nattac a da'ailo'oc (yacaré) puede conducirse a las profundidades acuáticas montado en el lomo del animal. Debido a este vínculo que establecen con determinados humanos, los shiguiỹac n'natac suspenden frente a ellos sus atributos predatorios y son plenamente capaces de comprender los mensajes que, en qom l'aqtaqa (lengua toba), le trasmiten los chamanes. Por último, algunos de estos "otros animales" pueden hablar la lengua qom, hecho que vulnera el principio establecido en el mito de origen pan-americano de la vagina dentada compartido por los toba (cf. Karsten 1932; Métraux 1946; Cordeu 1969-70; Palavecino 1969-70; Miller 1977; Tomasini 1978-79), de acuerdo al cuál los humanos se habrían apropiado de la capacidad de habla como atributo exclusivo.

\section{Los animales de las "otras personas"}

Así como existe una multiplicidad de "otras personas" que desarrollan una vida en las profundidades acuáticas, también forman parte de la zoología qom "otros animales" que viven sumergidos junto a ellas. Llama la atención que la mayoría de estos posean una forma externa similar a la de algún animal doméstico, hecho que los qom explican aduciendo que estos animales pertenecen a los shiỹaxaua "de abajo del agua". Un ejemplo de esto es caỹalo. Tal como describe Félix:

Caỹalo hay en el mar, algunos allá en Lapelole. [...] Cuando aparece, anuncia que va a crecer el río, ahí sale, pero ahí en el mismo lapel [laguna], ahí nunca se seca. Entonces, cuando sale, esto anuncia que va a haber mucha creciente, cuando sale a la noche, a la semana ya viene. Pero este no vive en el seco, sino ahí en el agua. Así como el [tamaño] grande del caballo, pero tiene una raya, tiene una raya así [en el lomo]. Pero el ojo así estaba. Grande el ojo, bien colorado el ojo, la crina muy larga, hasta acá, pasando el cogote. Y bueno, cuando sale, se puede ver y cuando no sale, no.

Buckwalter y Litwiller de Buckwalter mencionan que caỹalo es "el caballo del agua, un ser poderoso" (2001:5). Vuoto (1981b:135) refiere que el caballo del agua es un ser de menores dimensiones que el caballo terrestre y posee pelaje colorido y ojos colorados. Salvo estas dos menciones, no existe en la literatura otra referencia relativa a este animal. Según nuestra información, caỹalo no es un animal mítico, como señala Vuoto, sino un ser que -inmanente a la zoología qom-, nos ha sido ilustrado por medio de evidencia etnográfica que incluye dibujos (Figura 2) como el que Félix, un cazador de Riacho de Oro, produjo: 
Figura 2: Caỹalo (Dibujante: Félix Suárez)

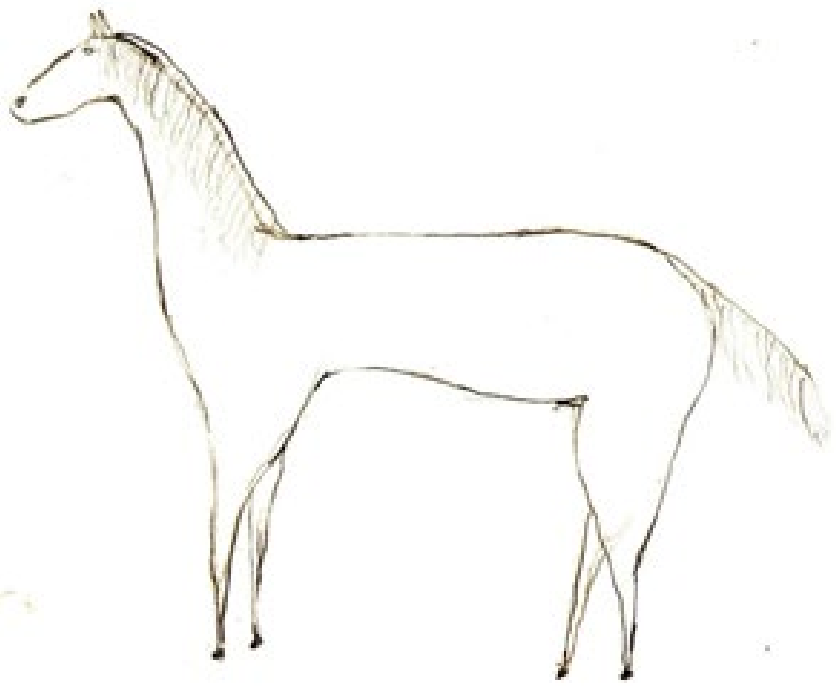

Otro de los animales que integran el elenco faunístico acuático es huaca Ita'a (Figura 3). Este ser, del cual no encontramos ningún tipo de referencia en la bibliografía chaquense, cuando se presenta fuera del agua, también anuncia que se aproxima una creciente del río. Su forma externa es similar a la de una vaca, pero "la guampa así de grande [un metro aproximadamente], lo mismo que la vaca, igual como búfalo, el búfalo tiene mucho cuerno, así también huaca lta'a" (Félix).

Figura 3: Huaca lta'a (Dibujante: Félix Suárez)

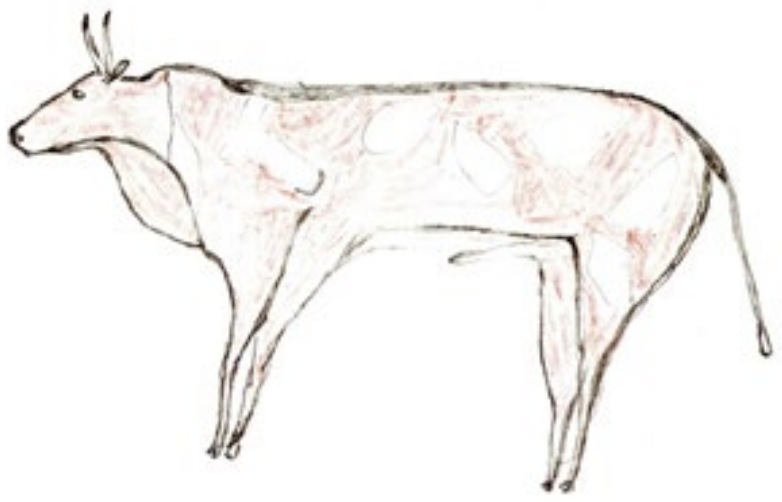


Fuera del dominio de los humanos también pueden encontrarse perros que viven o bien sumergidos en el agua o bien dispersos en el monte. Estos mismos, si bien tienen una corporalidad típicamente canina, poseen otras propiedades que los hacen particulares. De acuerdo a nuestra información, los perros del monte viven en ambientes poco degradados, en el "monte alto", siguiendo las palabras de los qom. Poseen largas orejas y un tamaño corporal que determina que estos dejen grandes huellas a su paso. Ernesto describió que en cierta oportunidad había ido a pescar pogoxosoxoi (cascarudo: Callichthys callichthys) junto a su abuelo y escuchó ladrar a estos perros. Este mariscador detalló: "una vez mi hermano agarró uno cachorrito y es mañero, arisco, y lo llevo a la casa y lo crio, era una perra grande, mala. A lo mejor ahora no hay más porque hay desmonte, esta todo topado, no sé a dónde se iban los perros". Esto da cuenta de la relación existente entre estos "otros animales" y los espacios que habitan. Caỹalo, huaca lta'a y los pioq (perro) del monte, en tanto seres con una corporalidad concreta y sus necesidades biológicas asociadas, se encuentran anclados a un lugar específico. La modificación del medio no sólo impacta en la vida de los qom, sino también en la fauna que ellos conocen y reconocen conformando el territorio.

Los perros de agua también se tornan visibles para los humanos cuando estos desarrollan actividades de caza y pesca. Julio describe que el abuelo de Laureano, un reconocido anciano de Riacho de Oro, tuvo la oportunidad de conocer personalmente a estos perros:

Esos perros que estaban afuera del agua, le vio cuando entraron esos perros en el agua y nunca salían. [...] Y esos perros son de ahí, del agua, del 'etaxat $l e^{\prime} c$ (ser del agua). Son iguales [a los perros], pero son muchos, cuando no está nadie en esa lacheugue (riacho), los perros están afuera. Igual que un chivo que vos ves que zambulle y no sale más, porque hay chivos del agua.

La evidencia etnográfica da cuenta de la existencia no sólo de los perros del agua, sino también de otros animales domésticos que, como los chivos, pertenecen a esas "otras personas" quienes desarrollan su vida en las profundidades.

Locolhue significa "diente largo" y es el nombre de un animal muy grande y peligroso que vive bajo el agua en lagunas grandes. ${ }^{13}$ De acuerdo a nuestra información, si bien es difícil encontrarlo, nadie mariscó jamás a locolhue. Los que lo han visto describen que tiene pelos raros igual que el carpincho, es brillante, más grande y más ancho que el tapir (Tapirus terrestris), posee el hocico chato y los dos dientes para arriba. Algunos aclaran que los doqshe (blancos) llaman hipopótamo a este animal. Valentín comentó que 
pudo observar a estos seres "en el zoológico y en la casa de un paraguayo que lo tenía en el fondo de la casa, en un arroyo profundo". Félix detalló que "hay en las lagunas grandes tipo Salado" y conoce precisamente la ubicación de un locolhue que habita en Lapelole cañole, una laguna que se encuentra próxima al río Bermejo en la provincia de Chaco.

Otra de las especies que poseen regímenes corporales diferentes a los animales típicos es el quiyoc (tigre: Panthera onca). Métraux menciona que para los tobas -aunque también para los abipones, mocovíes, matacos y vilelas-, "los eclipses se interpretan como ataques a la Luna o al Sol por parte de un jaguar celestial" (1996 [1946]:241, bastardillas nuestras). De acuerdo a su información, Tola ubica al "padre del jaguar" (quiyoc lta'a) en el tercer cielo (2012:80). Miller señala, en cambio, que quiyoc lta'a vive en las profundidades terrestres, es un 'alhua l'ec (lit. "ser de la tierra") (1979:38). Terán (1984), en su trabajo titulado La visión del kiyok en el mundo toba, si bien señala que el régimen corporal del tigre oscila entre la presencia concreta y la presencia como lqui'i, no alude a la existencia de tigres en otras esferas que no sean las terrestres. Nuestra información nos reveló la existencia de quiyoc 'etaxat le'c. El nombre de este ser indica, por un lado, su hábitat acuático $y$, por otro, su alto potencial transformacional debido a que integra al animal y a la persona en un mismo cuerpo. Otros qom aludieron que el nombre de este animal es quiyoc lpollo'. ${ }^{14}$

Los relatos que hacen referencia a este "otro animal" resaltan su carácter predador. Mauricio narró la historia de un mariscador que se encontraba meleando cerca de una laguna llamada Nere', próxima a Bermejito (Chaco) y, como sintió sed y agotamiento, se acercó a la orilla del agua para beber y descansar. De repente este hombre observó una ola gigante que se acercaba a donde estaba él y, como constató que no había viento, dedujo que se trataba de algo extraño y huyo barranca arriba. Mauricio concluyó: "Ese es el tigre del agua, pero él no vio el cuerpo. Pero así contó él, cuando quiere atrapar una persona tira el agua esa".

Otro evento relacionado a quiyoc 'etaxat le'c es el que protagonizaron dos pescadores qom y nos fue trasmitido por Vilo. ${ }^{15}$ Esos pescadores notaban que había algo en el agua y que se acercaba a ellos, "porque del medio del agua dice que salían burbujas y después salían olas y de a poquito se va acercando hacia la canoa", narró Vilo. Los pescadores se dirigieron velozmente a la orilla y uno de ellos alcanzó a descender pero el otro no pudo y "fue absorbido por ese ser que lo llevó abajo y ahí desapareció". El hombre que salió ileso corrió al campamento y contó a los otros lo sucedido. Allí se encontraba un chamán quién pergeñó una manera para matar al tigre del agua y vengarse así de lo que éste le había hecho al pescador. Entonces, mandó a construir una larga 
soga de fibras vegetales, se trasladó hasta el sitio del accidente y solicitó que se la ataran de la cintura. Luego, se sumergió, dejando un consejo: "mientras yo esté en la profundidad del agua, no tiren la soga hasta que yo no les haga señas con un tirón". Cuando los que quedaron en la orilla sintieron la seña, tiraron hacia afuera al chamán que traía al tigre muerto.

El pi'oxonaq (chamán) describió que el responsable de la muerte del pescador había sido este animal que lo había ahogado pero que no lo había comido, sino que "solamente lo mató y lo dejó al lado de la cueva". También mencionó que los tigres de abajo del agua tienen una cueva en la profundidad. De ahí fue que logró sacar al tigre y vio que "el tigre era tigre como el tigre del seco. Pero la diferencia de ese tigre es que ese tigre tiene el pelaje como el de cualquier pescado como el surubí (Pseudoplatystoma fasciatum) y el color es como el surubí". También refirió que "la palma de sus patas eran coloradas en señal de que eran especiales para el agua ya que nunca pisó la tierra". Las personas que recibieron el cadáver del quiyoc 'etaxat le'c comenzaron a cuerearlo pensando en la posibilidad de utilizar el cuero. Sin embargo, una vez que concretaron la misión, observaron que este nunca se secaba y que a medida que "lo ponían al sol salía agua y a cada rato se llenaba el cuero de agua y nunca podían lograr secarlo".

El suceso resumido, si bien resultó trágico, les permitió a los qom obtener información sobre las costumbres y el hábitat de este otro animal al que Vilo también nombró como quiyoc lpollo’ y Valentín ilustró (Figura 4):

Figura 4: Quiyoc acuático (Dibujante: Valentín Suárez)

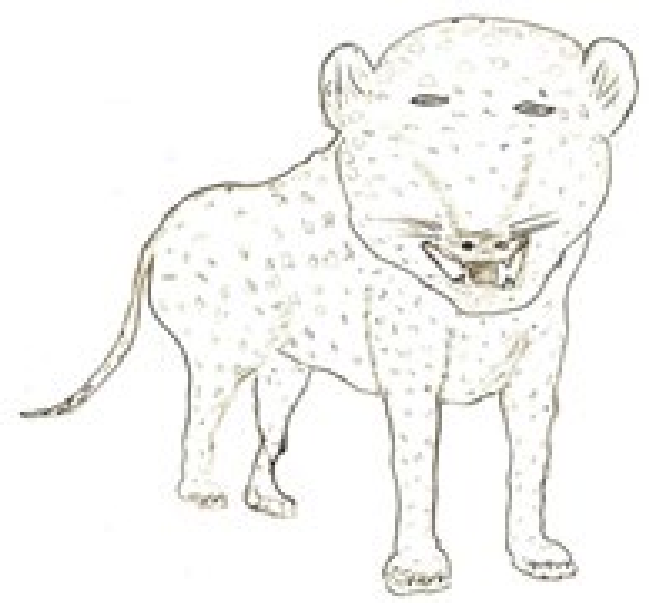


Asimismo, nuestra investigación nos permitió conocer la existencia de tigres que viven en las profundidades terrestres. Cuando le preguntamos a Félix su opinión respecto de la declinación de las especies zoológicas, especialmente la del tigre, respondió: "el tigre ahora no aparece pero el tigre está abajo de la tierra, el quiyoc abajo de la tierra y cuando viene un trueno cuando Satanás se desata, entonces todo se levanta, entonces aparece el tigre, entonces ese tigre va a volver otra vez cantidad". El relato presentado da cuenta de la articulación de los discursos qom con los provenientes del evangelio, especialmente con aquellos que presentan escenarios apocalípticos.

Finalmente, tal como describió Terán (1984), hemos hallado la presencia de tigres que, habitando sobre la superficie terrestre en los ambientes que regularmente ocupa el animal, desarrollan atributos fuertemente predadores. Mauricio explica que estos animales "son duendes", es decir, animales-hombres que se presentan tanto con forma de lqui'i (alma-espíritu) de tigre como con forma de no'ouet (no-humano cuidador del monte), y describe los hábitos de este ser cuando despliega su estado quiyoc:

Allá al oeste hay un tigre, pero no es un tigre de verdad, a veces está escuchando la gente como está gritando, pero no come gente, solamente los terneros, ovejas, cabritos. Pero nunca se vio, las huellas nomás, los animales tirados, restos de animales. Ellos dicen que no es un tigre porque el tigre tarde o temprano va a aparecer, pero ese nunca aparece. [...] Ese tigre, cuando mata un ternero, come el corazón nomás y ya está. No come más carne.

Como fue demostrado, estos "otros animales" habitan las profundidades acuáticas, la superficie terrestre o los espacios celestes. Dentro de este último lugar además ubicamos la presencia permanente de qasoxonaxa (el dueño del trueno), que puede observarse alternativamente como un elefante o como una tormenta, y temporal de quemoxonalo (la serpiente arcoíris), cuya forma corporal oscila entre la de una serpiente y un arcoíris- ambos responsables del despliegue de fenómenos climáticos- quienes ostentan éstos regímenes corporales altamente transformacionales.

\section{Animales blancos}

Los shiguiỹac lta'a o late'e son reconocidos porque presentan colores brillantes y bien definidos, diferentes a los que normalmente exhibe un animal de la misma especie. Nuestra información nos reveló asimismo la presencia de animales blancos. La hija de Graciela describió que a su mamá, mientras lavaba ropa en la laguna, se le apareció una tortuga grande 
y blanca. Esto provocó el susto de la mujer que no frecuentó más la zona. Otra habitante del barrio formoseño Namqom, quién también experimentó la presencia de una tortuga grande y blanca, expresó que "al tiempo apareció cuando dormía un viejo que era el demonio y me ofreció poder para solucionar el problema con las drogas y el alcohol de mis hijos". Chopa, un joven que solía mariscar cuises (Cavia aperea) de pequeño con la honda y bodoques, ${ }^{16}$ narró que una vez cazó uno de color blanco "y nadie me creía, todos venían a ver el conejo (cuis) blanco y por eso ahora no hay más conejos, porque, cuando aparece un conejo blanco, se van todos". Además, en El Desaguadero, nos trasmitieron que lo mismo ocurre con el carpincho: cuando aparece uno color blanco, indica que el resto se va a retirar para no retornar nunca al sitio. El mismo proceso se desata cada vez que ejemplares albos se tornan visibles antes la presencia de los cazadores, de acuerdo a la teoría que los qom me señalaron.

Los ejemplares blancos presagian peligros o infortunios. La anomalía de estos últimos es interpretada como un mensaje. Los cazadores comprenden que han presionado en exceso a la población animal, que decide desplazarse del sitio comunicándoselo a los humanos mediante un miembro de su especie llamativamente acromático. O, las mujeres entienden que deben abandonar el lugar que frecuentaban o permanecen alertas en pos de interpretar el significado de la aparición de ese "otro animal".

\section{La categoría "animal”}

La categoría shiguiỹac, si bien suele traducirse como "animal", no engloba a todos aquellos seres a los que la taxonomía occidental sí agrupa como tal (Figura 5). Dentro del grupo de los shiguiỹac se encuentran aquellos animales cuadrúpedos como los mamíferos, ${ }^{17}$ pero también se incluyen la iguana, el yacaré y el ñandú. Excluidos del conjunto de los shiguiỹac y aglomerados en el grupo de los maỹo se ubican todas las grandes aves, incluyendo al ñandú. Dentro de los coỹo se hallan pequeños pajaritos que también pueden ser clasificados como maỹo. Gran parte de los animales silvestres pueden ser incorporados como mascotas al ambiente doméstico, pasando a formar parte del grupo de los nlo dentro del cual se encuentran, además, los perros y gatos, gallinas, chivos, ovejas, vacas, caballos, etc. (Medrano et al. 2011; Medrano 2012). Los hualectapigui' están representados por todas aquellas especies que se arrastran por el piso como, por ejemplo, las víboras. El grupo de los nỹaq engloba la totalidad de los peces. 
Figura 5: Macrotaxonomía animal

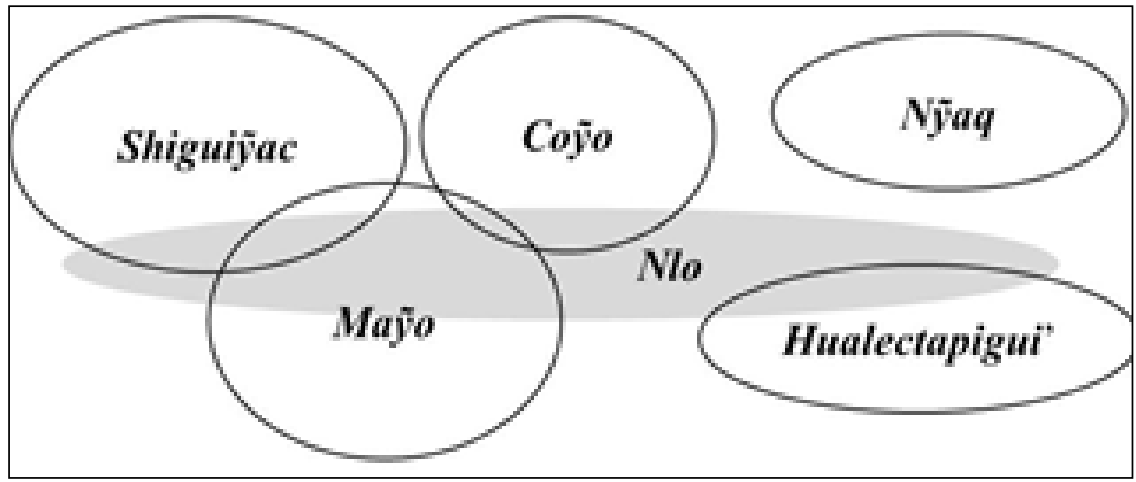

La información que presentamos nos conduce a concluir que no existe un término toba que signifique estrictamente "animal" equivalente al español y otras lenguas occidentales. Sin embargo, como ya señaló Brent Berlin (1992), la ausencia de una etiqueta nomenclatural no necesariamente implica la ausencia de una categoría. Al respecto, entre las generalizaciones que postula el autor, figura el principio según el cual, en la nomenclatura folk, la etiqueta para el rango de reino -como, por ejemplo, "animal" o "planta"- ocurre tardíamente en el desarrollo de una lengua (Berlin et al. 1973). Cúneo, menciona que "este es el caso también de la lengua toba, que no posee un nombre abarcador para referir al conjunto de las plantas" (2013:55). ${ }^{18}$ Sugerimos que, si bien no existe una etiqueta para denominar al conjunto de los animales, este conjunto existe como tal ${ }^{19}$ debido a una serie de rasgos que hemos señalado a lo largo de trabajo y sintetizamos en la Figura 1 presentada al inicio.

Evidencias como las que describimos han conducido a numerosos etnógrafos a reflexionar sobre la distinción entre los humanos y los animales en grupos indígenas de las tierras bajas amazónicas. Descola menciona que para los achuar "los hombres y la mayor parte de las plantas, de los animales y de los meteoros son personas (aents)". Luego, explica que así “se comprenderá mejor la ausencia de categorías supragenéricas nombradas que permiten designar al conjunto formado por las plantas o al conjunto formado por los animales, ya que el pueblo de los seres de la naturaleza forma conceptualmente un todo, cuyas partes son homólogas por sus propiedades" (1996:132).

Marco Antonio Gonçalves analizó, entre los pirahã de la Amazonía brasilera, la información que obtuvo empleando el concepto de "acción". Este mismo "engloba um conjunto de fenômenos e recursos simbólicos 
expressivos, através dos quais os pirahã apresentam o Cosmos e a relação entre os seres que o habitam". De acuerdo al autor, la "acción" pone al cosmos en operación y posibilita la construcción de una cosmología (2001:23, traducción nuestra). De acuerdo a esto, Gonçalves formuló que:

Por apresentar semelhanças que estabelecem diferenças, os animais ganham distintas classificações e podem se juntar, numa relação de sujeito, com os humanos, sem que deixem de ser animais. Um animal pode ser semelhante a um homem e continuar sendo um animal. Não há contradição nessa relação, pois o que ela evidencia são posições não contraditórias, nem irreconciliáveis; pelo contrário, a partir das diferenças os humanos e os animais estabelecem uma continuidade $(: 34)$.

La diferencia, en el pensamiento pirahã, no significa desigualdad (:35). Sin embargo, Gonçalves indica que en el contexto de las "acciones" es imposible tratar a los animales como una categoría, "la 'acción' instituye agentes, diferencias, más no dominios y clases" (:37-38). En este escenario el tapir, por ejemplo, no responde a un comportamiento relativo a lo que podríamos encontrar dentro de la clase animal, sino que actúa en un contexto de "acción", desarrollando posiciones diferenciadas e individualizadas en un esquema conceptual de acciones y reacciones.

Otro de los autores que cuestionan la separación categórica entre los humanos y los "demás animales" es Eduardo Viveiros de Castro. Según él, en el pensamiento yawalapíti, "não existe um conceito correspondente à nossa noção de 'animal (não humano)'; é impossível, portanto, fazer a Natureza corresponder a uma ideia geral de animalidade" (2002:45-46). Asimismo, Alexandre Surrallés constata que "no existe un término específico para designar al reino animal" en el léxico de los candoshi (2009:77). Este último autor sostiene que "parece primar la idea de que el cuerpo es la sustancia en desarrollo" rasgo que, al producir una comunidad de sustancia de toda la materia, debilita considerablemente los límites entre los seres (:77-78). Marc Lenaerts (2004) tampoco encontró términos genéricos para referirse a las categorías "plantas" y "animales" entre los ashéninka y cuestionó la idea misma de "taxonomía" debido que la "organización de los conocimientos [sobre el entorno biológico] permanece potencial, dinámica, siempre por reconstruir y redefinirse" (2004:36).

Nuestra información nos acerca más a la propuesta de Gonçalves (2001). Si bien entre los qom no existe un término que describa exactamente a la categoría animal, los animales -shiguiỹac, maỹo, coỹo, hualectapigui', nỹaq, nlo y los "otros animales"- son diferentes a los humanos -y a los "otros hu- 
manos". Esta diferencia, que está dada por divergencias en los regímenes alimentarios, reproductivos, capacidades comunicacionales, etc., no significa desigualdad. Humanos y animales en general continúan reunidos en aquel continuum que propone Descola y que se evidencia por la posesión generalizada de un lqui'i o el desarrollo de una interioridad común a la gran parte de los seres, y por las múltiples relaciones sociales que entre ellos se tejen. Sin embargo, en el plano de los vínculos, cada individuo (humano, animal, etc.) posee una etología, un régimen corporal que lo sitúa diferencialmente en la trama de la socialidad compartida.

\section{Repensando la taxonomía qom}

Hemos intentado demostrar cómo un esquema maniqueo que divida a humanos y no-humanos no resulta satisfactorio para detallar la complejidad que surge al analizar el entramado de relaciones entre los seres que participan de la sociocosmología qom. En este marco, presentamos un esquema alternativo que divide a los existentes en humanos, otros humanos, animales y otros animales. Este bosquejo fue construido en base a una continuidad interior y una discontinuidad que se traduce en diversos regímenes corporales. Ahora nos surgen dos interrogantes: ¿̇cuán pertinente es usar la etiqueta "otro" para referirse a humanos o animales distintos a los humanos y animales prototípicos? ¿Cómo funcionan estas categorías en un entorno altamente transformacional?

En ciencias sociales, el "otro" remite frecuentemente al otro cultural, quedando, por ende, fuertemente anclado a la definición de cultura. Nuestra intención no es entrar en estas fecundas pero extensas disquisiciones en torno a cómo se articulan los lazos de alteridad entre grupos culturales diversos, sino verificar si podemos sostener la presencia de "otros" al interior de estos grupos.

Bruce Albert (1992) analizó las representaciones yanomami de contacto con los blancos, mostrando cómo éstas fueron asociadas a diferentes "categorías de alteridad" a partir del sistema etiológico nativo. Aparecida Vilaça (2006) documentó cómo, en el contexto de las relaciones, los wari' objetivan la alteridad en la forma de afines, extranjeros, animales y enemigos, quedando los blancos incluidos en esta última categoría. Para la autora, "las llamadas categorías de la alteridad constituyen, ante todo, posiciones en un contexto relacional específico" (:30). Asumiendo esto último como válido, nos resulta lícito utilizar las categorías "otras personas" y "otros animales" para nombrar, dentro del universo qom, a aquellos existentes que no son estrictamente 
humanos o estrictamente animales. Es, en el plano de los vínculos que establecen los seres, que se definen como tales, asumiendo determinados comportamientos sociales. Para el desarrollo de estos roles fueron creados, desde los tiempos míticos, distintos regímenes corporales que definen una forma determinada de acercamiento a ese "otro" humano o animal.

En 2002 Albert y Alcida Rita Ramos organizaron una compilación de artículos con el objetivo de dar cuenta de cómo los indígenas veían a los antropólogos como "otros" en las situaciones de contacto. Mediante esta inversión, se pretendió "trata[r]-se de analisar as construções de nossa alteridade pelo Outro: o branco torna-se aqui 'objeto de outras antropologias'" (Albert 2002:10). Si esta inversión resulta, de acuerdo a los resultados expuestos por los autores, completamente posible, también lo sería una situación en donde los "otros humanos", por ejemplo, vean a los humanos como "otros" -y lo mismo podríamos pensar que ocurre para los animales. Claramente, un análisis de los seres enclavado en su alteridad adolece de complicaciones. Lejos de hacernos retornar a categorizaciones reduccionistas, esto nos condujo a replantear el esquema macro clasificatorio propuesto previamente (Figura 1). Con esta tensión, organizamos la Figura 6:

Figura 6: Una propuesta macro clasificatoria qom

\begin{tabular}{|c|c|c|c|c|}
\hline \multirow[t]{2}{*}{ Categoria enle } & HUMLNOS & No-HUMANOS & ANMLALS & NO-ANIMLIES \\
\hline & Personas & "Otras persoenas" & Animales & "Otros animales" \\
\hline Categoria emic & Shtjexama & Shtjaxama & $\begin{array}{l}\text { Shigulyac, Cojo, } \\
\text { Majo, Nyaq. } \\
\text { Hualectapigul", } \\
\text { No }\end{array}$ & 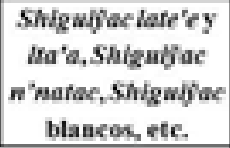 \\
\hline \multirow[t]{2}{*}{ Atributos } & \multicolumn{2}{|c|}{ Forma evterna humana } & \multicolumn{2}{|c|}{ Forma exterma animal } \\
\hline & $\begin{array}{l}\text { Refimen } \\
\text { corporal } \\
\text { peeferentemente } \\
\text { bamano }\end{array}$ & $\begin{array}{l}\text { Rtgimen } \\
\text { corporal distinto } \\
\text { al } \\
\text { pecferentemente } \\
\text { hamano }\end{array}$ & $\begin{array}{l}\text { Rhgimen corporal } \\
\text { preferentemente } \\
\text { animal }\end{array}$ & $\begin{array}{l}\text { Régimen corporal } \\
\text { distimto al } \\
\text { preferentemente } \\
\text { animal }\end{array}$ \\
\hline
\end{tabular}

Esta propuesta, al emplear las categorías humano y no-humano, permite continuar dialogando con aquellas etnografías que las consideran para sus análisis. Incorporamos a los animales y no-animales con el objeto de dar cuenta de una complejidad que encontramos producto de haber dialogado extensamente con los qom sobre su zoología. Si bien resulta evidente que en el trabajo de campo no hallamos una etiqueta clasificatoria que refiera a no-animales, tampoco encontramos -y no creo que lo hayan hecho otros 
etnógrafos- una que se refiera a los no-humanos. Nuestro fin es darle valor a la complejidad que describimos a lo largo de este artículo anclándonos en aquellas categorías emic que integran la praxis toba. Siguiendo a Viveiros de Castro, "nosotros no podemos pensar como los indios; no máximo, podemos pensar con ellos", y agrega, "el pensamiento indígena debe ser tomado-si se quiere tomarlo seriamente- como una práctica de sentido" (2010:210-211).

\section{Palabras finales}

En este trabajo, en base a la diversidad de regímenes, especialmente el hábitat y las costumbres alimenticias, a su poder transformacional y a su comportamiento predador, al tipo de comunicación que pueden desarrollar, hemos discriminado a los seres de la cosmología qom en función de cuatro categorías: humanos, no-humanos, animales y no-animales. Estas cuatro categorías no tienen un correlato exacto en la lengua indígena, así como no encontramos una palabra que englobe a la totalidad de los animales. Sin embargo, mostramos como las diferencias entre los shiỹaxaua (personas) y los shiguiỹac (animales) existen y justifican dicha separación. Esto último no suprime el hecho de que todos los seres se encuentren reunidos en aquel continuum que se evidencia por la posesión de un lqui'i o por el desarrollo de una interioridad común, y por las múltiples relaciones sociales que entre ellos se tejen. Ahora bien, en el plano de los vínculos, cada conjunto de individuos -humanos, no-humanos, animales y no-animales- poseen un régimen corporal que lo singulariza y contextualiza su accionar en la trama de una sociocosmología compartida.

No obstante, todas estas categorías funcionan en un entorno transformacional por lo que ellas no se presentan como fijas o estables (cf. Medrano 2013, 2014a). En palabras de Gilles Deleuze y Félix Guattari, “creemos en la existencia de devenires animales muy especiales que atraviesan y arrastran al hombre, y que afectan tanto al animal como al hombre" (2002:243-244). En este contexto, si bien las categorías nos orientan para pensar con los qom la manera en la que se organizan los vínculos con la fauna, las mismas no reifican el universo de los existentes, sino que tan solo organizan sus vínculos. Por el contrario, "lo que es real es el propio devenir, el bloque de devenir, y no los términos supuestamente fijos en los que se trasformaría el que deviene" (:244). Cuando la metamorfosis acontece, lo que se modifica son los vínculos posibles que ese "yo" puede desarrollar en relación a "otros". La tarea de construir taxonomías tiene, ante todo, una función social: organiza a existentes que, en devenir, sostienen la trama de la socialidad. Devenir es 
un verbo, como afirman Deleuze y Guattari, "que tiene toda su consistencia; no se puede reducir, y no nos conduce a 'parece', ni 'ser', ni 'equivaler', ni 'producir'" (:245). Devenir es una acción que humanos, no-humanos, animales y no-animales desarrollan en complicidad.

Finalmente, para comprender cómo los qom piensan y se vinculan con la fauna, tuvimos que remitirnos permanentemente al marco socicosmológico en el que se desarrolla la vida indígena. De esta manera reivindicamos la existencia en esta sociedad de una zoo-sociocosmología. Esta última, a diferencia de la zoología académica occidental, se ratifique en el trasfondo de una ontología donde las fronteras entre las categorías pueden franquearse por lo que las etiquetas clasificatorias funcionan organizando vínculos. En este estado de cosas, la taxonomía viene a redimir del caos a una sociedad igualmente protagonizada por humanos, no-humanos, animales y no-animales, viene a organizar deseos, acciones y necesidades antes que a genes y sus consecuencias biológicas observables, viene a mostrarnos todo lo complejamente social que es lo que al principio parecía una simple naturaleza, la de los qom.

\section{Agradecimientos}

Al Conicet por financiar esta investigación. A Florencia Tola por guiar generosamente mis derroteros zoo-sociocosmológicos por el Gran Chaco. A Paola Cúneo por asistirme en los áridos campos de la lingüística. A Valentín y Félix Suárez por su amistad y por asistirme en el campo con cariño y paciencia. A los qom que me enseñaron su zoología.

Recebido em 07 de agosto de 2015

Aprovado em 25 de abril de 2016

Celeste Medrano. Becaria posdoctoral CONICET. Instituto de Ciencias Antropológicas. Universidade de Buenos Aires, Buenos Aires/BA, Argentina. E-mail: <celestazo@hotmail.com>.

\section{Notas}

1 Entre quienes escribieron estas etnografías podemos nombrar, por ejemplo, a autores como Viveiros de Castro (2002), Lima (2005), Bonilla (2005), Vilaça (2006), Fausto (2008), Surrallés (2009) y Chaumeil (2010), entre otros. 
2 El Gran Chaco es el tercer gran territorio biogeográfico y morfoestructural de América Latina después del Amazonas y el Sistema Sabánico Sudamericano que incluye el Campo Cerrado Brasilero y las Sabanas colombo-venezolanas; el segundo en superficie cubierta por bosques después de las selvas pluviales tropicales del Amazonas y del Pacífico colombo-ecuatorianas, y el primero en fisonomías forestales de madera dura y muy dura; ocupa más de $1.000 .000 \mathrm{~km}^{2}$, extendiéndose por cuatro países, siendo el área desplegada en Argentina la más extensa, con aproximadamente $600.000 \mathrm{~km}^{2}$ (Morello et al. 2009).

3 Para la transcripción de las palabras y expresiones en toba utilizamos los siguientes símbolos fonéticos: /sh/ (fricativa palatal sorda), /q/ (oclusiva uvular sorda), /x/ (oclusiva uvular sonora), /'/ (oclusiva laríngea sorda), /ỹ/ (palatal sonora). Cf. Messineo (2003).

4 Para consultar otros trabajos que comprenden el análisis de la estratificación del universo toba, cf. Cordeu (1969-70), Terán (2000) y Wright (2008).

5 Utilizo el término existente en el sentido que Descola le da al mismo: "Cualquier cosa de la cual un ser humano piensa que existe ya sea porque posee una forma material o solamente conceptual" (Philippe Descola, comunicación personal en Tola [2013:27]).

6 Término empleado para referirse de forma general a las actividades de caza, pesca y recolección. A su vez, un "mariscador" es aquel que sale de su casa a realizar alguna o una combinación de estas acciones.

7 Nótese que Chaumeil (2010) utiliza la palabra "espíritus" para referirse a las madres de las especies animales y vegetales a pesar de atribuirles características similares a las de los humanos. Entre quiénes han trabajado el tema de los dueños de los animales y ambientes naturales en Amazonía, podemos citar a Descola (1996), Bonilla (2005), Fausto (2008), Surrallés (2009) y Chaumeil (2010), entre otros.

8 Género discursivo qom "cuya forma y contenido están relativamente estandarizados y son colectivamente reconocidos como propios por la comunidad de habla" (Messineo 2003:182).

9 Willerslev, quien trabajó con un grupo indígena de cazadores siberianos, los yukaghirs (2004), usa el término no-animal como cierre de un artículo donde propone un giro a ciertos problemas que encuentra en el perspectivismo. El cazador usa actos de mimesis para lograr lo que el autor ha llamado una "doble perspectiva", que permite asumir el punto de vista de la presa, sin dejar de ser una persona humana con intención 
de cazar: "Por lo tanto, el perspectivismo entre los Yukaghirs [...] consiste en no renunciar a un solo punto de vista. Tiene que ver con la acción entre las identidades, en ese espacio doble-negativo que he caracterizado como 'no animal, no es no-animal'" (:648649 , traducción nuestra). Salvo esta cita, no se menciona a la categoría no-animal en otras obras de tenor científico por lo la presente contribución resulta pionera al respecto.

10 Esta división, realizada con fines analíticos, no responde a ninguna clasificación sostenida por los qom quienes agrupan a animales y "otros animales" bajo la categoría de shiguiỹac. Volveremos sobre esto al final.

11 No todos los n'natac son animales, algunos son "otras personas", como no'ouet, 'araxanaq late'e, qosorot, etc.

12 Tola (2007), en su estudio sobre el cuerpo entre los qom, explica que aunque el lqui'i es generalmente traducido como alma o espíritu por quienes han desarrollado estudios en el Chaco, este tiene ciertas habilidades que le impiden ser reducido a estas nociones. La autora explica que: "O lqui'i permite tanto aos humanos quanto aos não humanos (espíritos xamânicos, mortos, mestres das espécies etc.) a capacidade reflexiva, a intencionalidade, a comunicação, assim como a percepção visual" (:505). Así, en tanto propiedad no exclusiva de los seres humanos (cf. Medrano et al. 2011; Medrano 2012 para una descripción sobre el lqui'i en los animales), condensa los caracteres de interioridad que, en términos descolianos, nos permite identificar como animista a esta sociedad indígena.

13 Buckwalter y Litwiller de Buckwalter indican que la palabra locolhue se refiere a "foca, lobo marino, elefante" (2001:83).

14 Buckwalter y Litwiller de Buckwalter refieren que quiyoc lpollo' es "el tigre del agua" (2001:174).

15 Este relato fue recogido junto con Florencia Tola y Valentín Suárez en la comunidad Km 503 durante un trabajo de campo en 2011.

16 Los bodoques son pequeñas piezas esféricas que los jóvenes fabrican con barro y dejan secar al sol. Las mismas son empleadas como proyectiles que, propulsados mediante hondas, les permiten cazar cuises y aves.

17 Tola propuso una clasificación según la cuál "los shiguiỹac estarían representados por los animales cuadrúpedos, los maỹo por grandes animales con plumas 
y bípedos, lo coỹo por pequeños animales con plumas y bípedos, los hualectapigui' por animales que se arrastran, los nỹaq por peces, y los nlo' por animales domésticos" (2009:126, traducción nuestra).

18 En concomitancia con lo enunciado por Berlin (1992) para muchos pueblos cazadores-recolectores, Scarpa (2010) documenta la ausencia de una etiqueta que refiera al reino vegetal entre los chorote, otro grupo indígena chaqueño. Idoyaga Molina llega a la misma conclusión trabajando con los pilagá y agrega que "la sistemática indígena muestra un haz de relaciones categoriales que comparado con la científico-occidental exhibe una continuidad entre conceptos 'etnobotánicos' y 'cosmológicos' [...]. Para los pilagá no son menos taxonómicas la ideas de payák [poder] o logót [jefe o dueño] que las de 'epáq [árbol] o naná [plantas cultivadas]" (1990-91:17).

$19 \mathrm{Al}$ respecto Idoyaga Molina afirma que, para la clasificación animal pilagá, "las familias o los órdenes-aunque pueden ser descubiertos- no son habitualmente categorías taxonómicas" (1995:261).

\section{Referencias bibliográficas}

ALBERT, Bruce. 1992. "A fumaça do metal: história e representações do contato entre os Yanomami". Anuário Antropológico, 89:151-189.

2002. "Introdução. Cosmologias do contato no Norte-Amazônico". In: B. Albert \& A. R. Ramos (orgs.), Pacificando o branco. Cosmologias do contato no Norte-Amazônico. São Paulo: Editora Unesp. pp. 9-21.

ALBERT, Bruce \& RAMOS, Alcida Rita. 2002. Pacificando o branco. Cosmologias do contato no Norte-Amazônico. São Paulo: Editora Unesp.

BERLIN, Brent. 1992. Ethnobiological classification. Principles of categorization of plants and animals in traditional societies. Princeton: Princeton University Press.

BERLIN, Brent; BREEDLOVE, Dennis \& RAVEN, Peter. 1973. "General principles of classification and nomenclature in folk biology". American Anthropologist, 75(1):214-242.
BONILLA, Oiara. 2005. “O bom patrão e o inimigo voraz: predação e comércio na cosmologia Paumari". Mana. Estudos de Antropologia Social, 11(1):41-66.

BRAUNSTEIN, José. 1983. Algunos rasgos de la organización social de los indígenas del Gran Chaco. Buenos Aires: Trabajos de Etnología, 2.

BUCKWALTER, Alberto \& LITWILLER de BUCKWALTER, Lois. 2001. Vocabulario toba (Edición revisada). Elkhart, Indiana, USA: Equipo Menonita.

CERIANI CÉRNADAS, César. 2013. “Entre la confianza y la sospecha. Representaciones indígenas sobre las experiencias chaqueñas de misionalización protestante". In: F. Tola; C. Medrano \& L. Cardín (eds.), Gran Chaco. Ontología, poder, afectividad. Buenos Aires: Rumbo Sur. pp. 297-320.

CHAUMEIL, Jean-Pierre. 2010. “Des sons et des esprits-maîtres en Ama- 
zonie amérindienne". Ateliers du LESC, 34. Disponível em : http:// ateliers.revues.org/8546. Acesso em 06/06/2012.

CORDEU, Edgardo. 1969-70. "Aproximación al horizonte mítico de los tobas". Runa, 12(1-2):67-176.

CORDEU, Edgardo \& SIFFREDI, Sandra. 1971. De la algarroba al algodon. Movimientos milenaristas del Chaco argentino. Buenos Aires: Juárez Editor.

CUNEO, Paola. 2013. Formación de palabras y clasificación nominal en el léxico etnobiológico en toba (guaycurú). Lincom Studies in Native American Linguistics 68. Munich: Lincom Europa.

DELEUZE, Gilles \& GUATTARI, Félix. 2002 [1980]. Mil mesetas. Capitalismo y esquizofrenia. Valencia, España: Pre-Textos

DESCOLA, Philippe. 1996 [1986]. La selva culta, simbolismo y praxis en la ecología de los achuar. Ecuador: Abya Yala . 2012. Más allá de naturaleza y cultura. Buenos Aires: Amorrortu.

FAUSTO, Carlos. 2008. "Donos demais: maestria e domínio na Amazônia". Mana. Estudos de Antropologia Social, 14(2):329-366.

GONÇALVES, Marco Antonio. 2001. O mundo inacabado. Ação e criação em uma cosmologia amazónica. Rio de Janeiro: Universidade Federal do Rio de Janeiro.

IDOYAGA MOLINA, Anatilde. 1990-91. "Taxonomía y cosmología en la etnobotánica pilagá". Scripta Ethnologica, 13:11-22.

. 1995. Modos de clasificación en la cultura pilagá. Buenos Aires: Centro Argentino de Etnología Americana.

KARSTEN, Rafael. 1932. Indian tribes of the Argentine and Bolivian Chaco. Helsingfors: Societas Scientiarum Fennica.
LATOUR, Bruno. 2004. Política da natureza: como fazer ciência na democracia. Bauru, Brasil: Editora da Universidade do Sagrado Coração. 2007 [1991]. Nunca fuimos modernos. Argentina: Siglo XXI.

LENAERTS, Marc. 2004. "Taxonomías ashéninka". In: O. Calavia Sáez, M. Lenaerts \& A. M. Spadafora (eds.), Paraíso abierto, jardines cerrados. Pueblos indígenas, saberes y biodiversidad. Quito, Ecuador: Abya Yala. pp. 31-52.

LIMA, Tânia Stolze. 2005. Um peixe olhou para mim. O povo Yudjá e a perspectiva. São Paulo: Editora Unesp/ Rio de Janeiro: NuTI.

MEDRANO, Celeste. 2012. Zoo-sociología qom: de cómo los tobas y los animales trazan sus relaciones en el Gran Chaco. Ph.D. Dissertation, Facultad de Filosofía y Letras, Universidad de Buenos Aires, Argentina. . 2013. "Devenir-en-transformación: debates etnozoológicos en torno a la metamorfosis animal entre los qom". In: F. Tola; C. Medrano \& L. Cardín (eds.), Gran Chaco. Ontología, poder, afectividad. Buenos Aires: Rumbo Sur. pp. 77-101.

. 2014a. “Los ‘bichos' del chamán. Chamanismo y metamorfosis de insectos en la zoo-sociocosmología qom". In: E. M. Costa Neto (org.), Entomologia cultural: ecos do I Simpósio Brasileiro de Entomologia Cultural - 2013. Feira de Santana: UEFS Editora (en prensa).

. 2014b. "Zoo-sociocosmología qom: seres humanos, animales y sus relaciones en el Gran Chaco". Journal de la Société des Américanistes, 100(1): 233-265.

MEDRANO, Celeste; MAIDANA, Mauricio \& GÓMEZ, Cirilo. 2011. Zoología qom. Conocimientos tobas sobre el mundo animal. Serie Naturaleza, 
Conservación y Sociedad, 3. Santa Fe: Ediciones Biológica.

MESSINEO, Cristina. 2003. Lengua toba (guaycurú): aspectos gramaticales y discursivos. Múnich: Studies in Native American Linguistics , 48, Lincom Europa.

MÉTRAUX, Alfred. 1946. Myths of the Toba and Pilagá indians of the Gran Chaco. Philadelphia: American Folklore Society. 1996 [1946]. Etnografía del Chaco. Paraguay: El Lector.

MILLER, Elmer S. 1977. "Simbolismo, conceptos de poder y cambio cultural de los toba del Chaco argentino". In: L. Bartolomé \& E. Hermitte (eds.), Procesos de articulación social. Buenos Aires: Amorrortu. pp. 305-338.

1979. Los tobas argentinos. Armonía y disonancia de una sociedad. México: Siglo Veintiuno.

MORELLO, Jorge H.; RODRÍGUEZ, Andrea F. \& SILVA, Mariana. 2009. "Clasificación de ambientes en áreas protegidas de las ecorregiones Del Chaco húmedo y seco". In: J. H. Morello \& A. F. Rodríguez (eds.), El Chaco sin bosques: la Pampa o el desierto del futuro. Buenos Aires: Orientación Gráfica. pp. 53-91.

PALAVECINO, Enrique. 1969-70. "Mitos de los indios tobas". Runa, 12(12):177-197.

SCARPA, Gustavo. 2010. "Hacia una etnotaxonomía vegetal chorote II: clasificación de las plantas entre las parcialidades iyojwá'ja y iyowújwa del Chaco argentino". In: C. Messineo; G. Scarpa \& F. Tola (comps.), Léxico y categorización etnobiológica en grupos indígenas del Gran Chaco. La Pampa: Universidad Nacional de La Pampa. pp. 157-198.

SURRALLÉS, Alexandre. 2009 [2003]. En el corazón del sentido, percepción, afectividad, acción en los candoshi,
Alta Amazonía. Perú: Instituto Francés Estudios Andinos y Copenhague, IWGIA.

TAYLOR, Anne Christine. 1998. "Corps immortels, devoir d'oubli: formes humaines et trajectoires de vie chez les Achuar". In: M. Godelier \& M. Panoff (eds.), La production du corps: approches anthropologiques et historiques. Amsterdam: Editions des Archives Contemporaines: pp. 317-338.

TERÁN, Buenaventura. 1984. "La visión del kiyok en el mundo toba". Suplemento Antropológico, 19(2):169-208. 2000. “Los ámbitos geográficos conocidos por los Tobas orientales y las nociones cosmovisionales vinculadas a los mismos". Casa Tomada, 6(13). Disponível em: http://www. edicionesjuglaria.com.ar/revistacasatomada.htm. Acesso em 04/07/2008.

TOLA, Florencia. 2007. "'Eu não esto só(mente) em meu corpo'. A pessoa e o corpo entre os toba (qom) do Chaco argentino". Mana. Estudos de Antropologia Social, 13(2):499-519.

2009. Les conceptions du corps et de la personne dans un contexte amérindien. Indiens Toba du Gran Chaco sudaméricain. París: L'Harmattan. 2010. "Maîtres, chamanes et amants. Quelques réflexions sur la conception toba de l'agentivité". Ateliers du LESC, 34. Disponível em: http://ateliers.revues.org/8538. Acesso em 27/09/2010.

. 2012. Yo no estoy solo en mi cuerpo. Argentina: Biblos.

. 2013. "Introducción: acortando distancias. El Gran Chaco, la antropología y la antropología del Gran Chaco". In: F. Tola; C. Medrano \& L. Cardin (eds.), Gran Chaco: ontologías, poder, afectividad. Buenos Aires: Rumbo Sur. pp. 11-36.

TOMASINI, Juan Alfredo. 1978-79. “La narrativa animalística entre los toba 
de occidente". Scripta Ethnológica, 5(1):52-81 .

VILAÇA, Aparecida. 2006. Quem somos nós: os Wari' encontram os brancos. Rio de Janeiro: Editora da UFRJ.

VIVEIROS DE CASTRO, Eduardo. 2002. A inconstância da alma selvagem. São Paulo: Cosac \& Naify. . 2010. Metafísicas caníbales. Líneas de antropología postestructural. Buenos Aires: Katz.

VUOTO, Diego Luis. 1981a. Aspectos de la interrelación entre la fauna y la cultura Toba-Taksek. Tesis de Licenciatura, Facultad de Filosofía y Letras, Universidad de Buenos Aires, Argentina. 1981b. "La fauna de los Toba-Taksek". Entregas del Instituto de Tilcara, 10:77-138.

WILLERSLEV, Rane. 2004. "Not animal, not no-animal: hunting, imitation and empathic knowledge among the Siberian Yukaghirs". The Jornal of the Royal Anthropological Institute, 10(3):629-652.

WRIGHT, Pablo G. 2002. "L'evangelio: pentecôtisme indigène dans le Chaco argentin". Social Compass, 49(1):4366.

2008. Ser-en-el-sueño. Crónicas de historia y vida toba. Buenos Aires: Biblos. 
LOS NO-ANIM ALES Y LA CATEGORÍA

"ANIMAL". DEFINIENDO LA ZOOSOCIOCOSMOLOGÍA ENTRE LOS TOBA (QOM) DEL LOS CHACO ARGENTINO

\section{Resumen}

En este artículo se analizan las categorías en las que se divide el mundo de los existentes entre los toba (qom) del Chaco argentino. La propuesta se basa en comparar atributos que definen a los humanos y a los no-humanos con el fin de complejizar a estos últimos dentro de los cuales se encuentran los animales. En primer término, se examinan algunas particularidades del aspecto externo, las preferencias alimentarias, el régimen sexual y reproductivo y el comportamiento y hábitat de aquellos a los que los toba llaman shiỹaxaua (persona) para, en una segunda parte, explorarlas entre quienes son identificados como "animales". Finalmente, se problematiza la categoría "animal" y se propone una macrotaxonomía que aporta un marco de análisis dentro del cual se pueden ahondar aspectos de la zoo-sociocosmología de este grupo indígena.

Palabras clave: no-animales; macro-taxonomía, qom; toba; Gran Chaco.
NÃO-ANIMAIS E A CATEGORIA

"ANIMAL". DEFININDO A ZOOSOCIOCOSM OLOGIA ENTRE OS TOBA (QOM) DO CHACO ARGENTINO

\section{Resumo}

Neste artigo, são analisadas as categorias a partir das quais se divide o mundo dos existentes entre os Toba (Qom) do Chaco argentino. A proposta baseia-se na comparação de atributos que definem os humanos e não humanos com a finalidade de complexificar estes últimos, dentro dos quais se encontram os animais. Em um primeiro momento, são examinadas algumas particularidades do aspecto externo, as preferências alimentares, o regime sexual e reprodutivo, o comportamento e habitat daqueles a quem os Toba denominam shiỹaxaua (pessoa) para, em um segundo momento, explorá-las entre aqueles identificados como "animais". Finalmente, problematiza-se a categoria "animal" e propõe-se uma macrotaxonomia que fornece um marco de análise dentro da qual podem ser aprofundados os aspectos da zoosociocosmologia deste grupo indígena.

Palavras-chave: Não animais, Macrotaxonomía, Qom, Toba, Grande Chaco. 
NON-ANIMALS AND THE "ANIMAL"

CATEGORY. DEFINING THE ZOOSOCIOCOSM OLOGY OF THE TOBA (QOM) OF THE ARGENTINIAN $\mathrm{CHACO}$

\begin{abstract}
This article analyses the categories that classify the world among the Toba (Qom) of the Argentinian Chaco. It compares the attributes that define humans and non-humans in order to reveal the complexity of the latter category, which includes
\end{abstract}

animals. First, it examines certain peculiarities of the appearance, food preferences, sexual and reproductive regimes, behaviour and habitat of those animals that the Toba call shiyaxaua (person), and then explores the same features among those that they identify as 'animals'. Finally, it problematizes the category of the "animal" and proposes a macrotaxonomy that provides an analytical framework within which we can expand aspects of these Amerindian's zoo-sociocosmology.

Keywords: non-animal; macro-taxonomy, Qom; Toba; Gran Chaco. 